\title{
Towards Supplier Maturity Evaluation in Terms of PLM Collaboration
}

\author{
Sara Mahdikhah ${ }^{1}$, Mourad Messaadia ${ }^{1}$, David Baudry ${ }^{1}$, Thierry Paquet ${ }^{2}$, Anne Louis ${ }^{1}$, \\ Bélahcène Mazari ${ }^{1}$, Richard David Evans ${ }^{3}$, and James Xiaoyu Gao ${ }^{3}$ \\ ${ }^{1} \mathrm{CESI} /$ IRISE, Rouen, France \\ \{smahdikhah, mmessaadia, dbaudry, alouis, bmazari\} acesi.fr \\ ${ }^{2}$ University of Rouen /LITIS, France \\ Thierry.Paquet@univ-rouen.fr \\ ${ }^{3}$ University of Greenwich, Chatham Maritime, Kent, United Kingdom \\ $\{$ R.D.Evans, J.Gao\}@gre.ac.uk
}

\begin{abstract}
The product lifecycle management (PLM) system has a significant role to support the collaboration and manage the partnership between OEM and supplier to enable the success of supplier integration. Today great rates of cooperation as suppliers have been dedicated to SMEs.

Since one of the PLM task is to control the collaboration between OEM and suppliers, this paper provide supplier (SMEs) a framework to find their level of relationship with OEM and the steps that they can improve it. To respond to this trend, we defined a methodology based on collaborative matrix maturity levels and four PLM axes of strategic, organization, process and tools levels. Finally according to this matrix, we proposed a structure of a proper questionnaire and example that shows suppliers how to evaluate their positions in terms of collaboration in PLM.
\end{abstract}

Keywords: PLM, OEM/Supplier Collaboration, Collaboration maturity.

\section{$1 \quad$ Introduction}

Technology of PLM is composed of complex process involve challenges of organization in terms of information flow, management of human resource and different relation levels between OEM and suppliers [1].

The integration of supplier in value chain of product is not a new challenge. Various researches and projects have been focused on this issue that seeks more efficient ways to improve integration. In this study we found researches with aspect of interoperability [2], data exchange [3] and those ones that consider organization between OEM and its supplier, through the development of different level of cooperation and integrate the suppliers in the network.

The suppliers in the field of automotive are looking for new innovative ways to propose high quality of product and platform while the costs are faire. According to high demand for rapid development of innovation, high quality and increased regulation, it will be apparent that the favorite suppliers are those ones who focus on

B. Grabot et al. (Eds.): APMS 2014, Part I, IFIP AICT 438, pp. 201-208, 2014.

(C) IFIP International Federation for Information Processing 2014 
leverage the innovative products with grow development in new platforms and programs. Therefore for OEMs, especially in the domain of automotive, it will be important to seek new trends of development that involves supplier integration into the product development process chain. To respond to this need of supplier integration, it seems to be necessary to deal with PLM framework and tools that focus on integration of supplier and on collaboration between OEM [4].

The classic works until the last few years have had a great revolution in industry. The evolution was characterized in the network of OEM and suppliers with a vertical cooperation method. This approach was the result of integration of supplier's equipment through the simultaneous process of development in automotive industries in different phases such as planning, design and education [5].

According to aims of BENEFITS project to understand the challenges relating to knowledge management and sharing cooperation of supplier and OEM, an industrial investigation was conducted during six months in UK. The result obtained from previous questionnaires persuaded us to investigate about different levels of collaboration between OEM and SMEs from begging steps to the optimal level. This framework can help suppliers (SMEs) to assess their positions in this cooperation and provide them perspective of an optimal cooperation. In addition more we will propose a structure of proper questionnaire that prepare the supplier's manager to benchmark the situation of level of collaborating and be able to answer some key questions such as:

- What are the activities of each level of co-PLM?

- What is the actual level of collaboration?

- What are the requirements elements to improve the level of collaboration?

The paper is organized as different sections. The next part addresses the PLM approach in term of collaboration between OEM and suppliers. Section three analyses the state of the art in term of collaboration level between suppliers (SMEs) and OEMs. The results of presenting a framework and assessment level of collaboration is presented in section forth. Finally, we conclude and discuss future works according to BENEFITS project in fifth part.

\section{PLM Approach in Term of Collaboration between OEM \& Suppliers}

Nowadays the enterprises seek new collaborative business methods to solve their new challenges. They wish these solutions be able to change the global marketing of the product by leveraging the power of product collaboration across different parts of value chains such as partners, employees, suppliers, and customers. In addition more, the methods must provide them a faster product development, more efficiency in managing of their programs. Also this collaborative program that involve product and supply chain processes should be able to reduces development costs, increase product innovation, make the time of marketing faster and to have a significant result on revenue. It is expected that the methods of PLM collaborative programs impacts on 
technical advantages as to provide more effective partnership for PLM users, delete the barriers to innovation and finally increase the customer satisfaction [5].

In order to reduce the expenditure of collaborative programs, OEM -especially in automotive industries- prefer to have direct connection to suppliers with limit number of capable and effective suppliers that called system supplier. In this system, there is no direct link between other suppliers which calls sub -supplier with OEM but instead the system supplier works closer to OEM and in a another hand deals with subsupplier and manage theirs task and coordination [6].

Many OEM and supplier networks in automotive industry which have been developed in 1980's are characterized by "vertical cooperation". This cooperation often starts with request of OEM to supplier for producing a product according to its precise specifications and OEM will keeps the industrial properties of their products, responsibility and the product band. In addition more, this relationship can be evolved to the level of co-development between OEM and suppliers.

In the automotive industry, vertical partnership has a significant effect in different aspects such as integration of equipment suppliers in a simultaneous development process of cars, planning, design and implementing.

More over in the aerospace industry, we will face three kinds of vertical partnerships (OEM/supplier) such as, classical relationship with OEM dominance that Boeing can be as an example, Cooperative model with example of Airbus and finally those ones that OEM's role is limited to the level of integration in purchased part [7]. The implementing of such collaboration requires organizing effective communication between enterprises through integration and interoperability on different levels (Fig. 1)

\begin{tabular}{cc|}
\hline PLM axes & \multicolumn{1}{c|}{ Interoperability level } \\
\hline Strategy & PLM Goals, organization mode \\
\hline Organization & Skills, Best practices, Ontology \\
\hline Process & $\begin{array}{l}\text { Standards, Process synchronization,proces: } \\
\text { models, Ontology }\end{array}$ \\
\hline Tools & Implametation,Data models
\end{tabular}

Fig. 1. Interoperability through PLM axes

In this paper, to keep up with these tasks above, a PLM collaboration framework is established, enabling supplier to assessment their actual level of collaboration to OEM and the steps to improve their partnership. 


\section{Levels of Collaboration in PLM}

In order to reach to a successful developed business and issues related to PLM such as processes or information, it seems to be necessary that the actual situation of every unit of business, regional unit or product area be recognized and understood well. The PLM maturity model is a suitable tool for this evaluation and analysis [9].

The exist PLM maturity model refers to the generic maturity model CMM by means of COBIT standard [10]. This matrix with five rough levels describes how a company and its management team are able to use and extend a corporate-wide PLM concept and related processes and information systems. These stages represent the organizational growth, learning, and development and they allow analysing the maturity of the enterprises during this cooperation [10]. Although in concept of collaboration in PLM, benefit of PLM system in network of SMEs are rare but is an attractive subject for researchers of this domain in recent years [11, 12, 13, 14, 15]. Among them one study has investigated the adoption of PLM system in SMEs network by means of 11 case studies. This research tackles related problems and tries to accomplish a crucial task in PLM to evaluate the achieved benefits. In order to do this, they defined a methodology to assess PLM advantages according to a defined industrial target by means of some quantitative indicators such as time and cost. These SMEs are classified to three groups. The first stages related to those one that there are no use of advanced communication and management technology and Communication took place by traditional ways. In second stage, a commercial PDM system is conducted and data sharing improves in a standard way and finally in stage three the network of suppliers deals with evolution of exiting PDM tools toward a PLM approach which leads to a good trade-off between some commercial collaborative product definition management tools and the most advanced computer supported cooperative work applications [16].

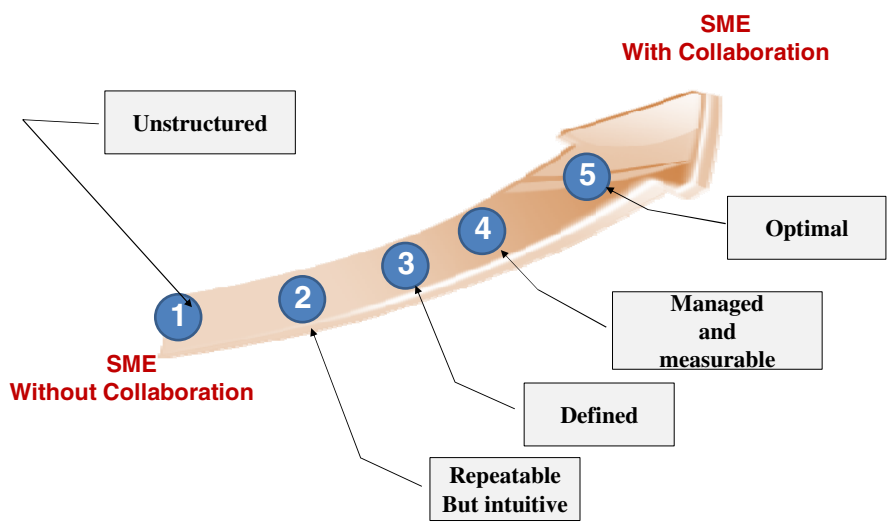

Fig. 2. Levels of SMEs collaboration through PLM based on [10] 
Intense pricing and limit of time will force the OEMs to work with the suppliers that provide them faster and more accurate responses. A PLM system called NSK (Nanjing-Fiat Solution Kit) has been established to make the collaboration between an OEM called Nanjing-Fiat and suppliers, exchanging files and key information about vehicles faster and more efficient.

In this PLM system a web-based tool can be used by both OEM and suppliers for the operations such as uploading, browsing, exchanging, and downloading of data relates to product requirements for specific vehicle systems. NSK PLM system will present in three different levels of stagey, technique and operation level.

At the strategy level, the PLM strategy focusing on supplier integration. At the technical level the tools to enable supplier integration have been selected and finally at the operation level, the PLM system is going to be implemented [17].

In this study according to the investigation, different PLM system and existing maturity models, we presented a PLM framework in section 5, based on maturity models of PLM and four axes: strategic, organization, process and tools.

\section{PLM Framework and Assessment the Level of Collaboration between OEM and Supplier}

In this section we will introduce a framework of maturity level of collaboration between OEM and Suppliers which called SPOT. In continue we will present a structure of questionnaire to provide supplier's manager assess their place of collaboration in a better way. (Table1).

\subsection{Discussion}

For improving our framework we need to propose a structure of questionnaire and apply it to different enterprises (OEM/Supplier) to have Feedbacks. These feedbacks will be used to improve the table for the levels validation.

For this questionnaire we need to choose the right person for having the best answer. That's why we adopt different levels in our approach. These levels will be as:

- Strategic level: will address Top management.

- Organization level : will address managers, departments responsible,

- Process level: will address managers and engineers, and team head etc.

- Tools level: we will address all technical staff

We will formalize questions in order to replace the Supplier (SME) directly in the right level. As an example, in the strategic axe we have five levels; in each level we have some activities. One of these activities concerns the PLM concept, in which evolves from one level to another. In the level1, Unstructured Collaboration, we have "work must be done to define the PLM concept". In the second level, partial but intuitive collaboration, we have "PLM concepts are defined but not formalized", etc. 
In order to identify the right level for each activity, questions will be addressed to the Boss/Managers and structured as follows:

In your opinion, what is the best definition of PLM concept?

Is it defined in your enterprise?

Table 1. PLM framework and assessment the level of collaboration of OEM and supplier

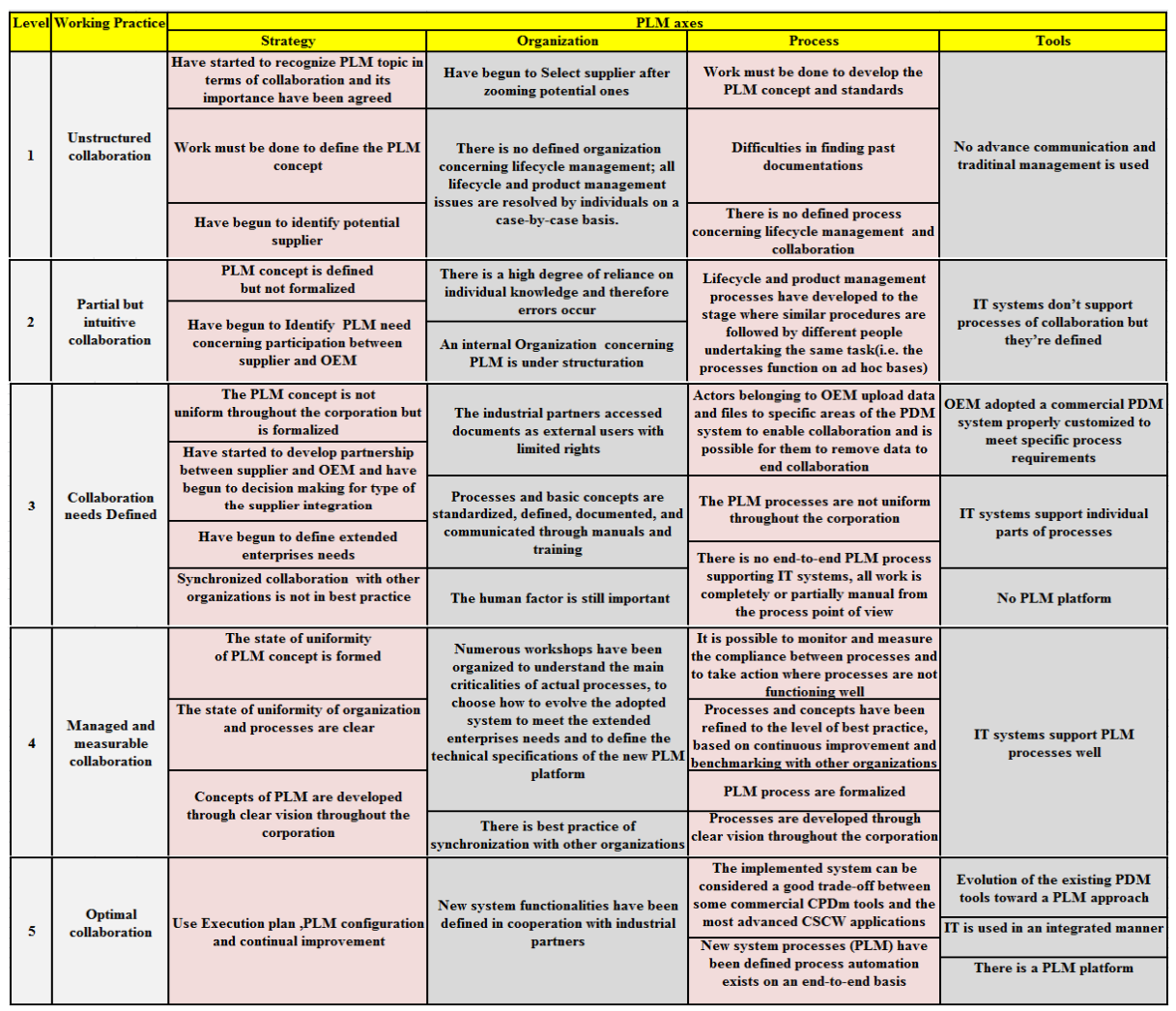

- If No = L1

- If $\quad$ Yes $\geq \mathrm{L} 2$

Is it formalized in your enterprise?

- If $\mathrm{No}=\mathrm{L} 2$

- If Yes $\geq$ L3

Is the PLM concept integrated uniformly throughout your enterprise?

- If No = L3

- If Yes $\geq \mathrm{L} 4$ 
For taking decision, we need to develop all questions in the same way and cross different answers. Since the framework is based on existing states of the art reviews, we still need to improve the table and to validate previous questions by investigations.

Furthermore uniformity of questions is very important. As seen before, each question must be linked to the related level. In continue we will assign weights to questions according to their importance in the PLM adoption. This will give a unique result related to each level, even if it is arbitrary and we can give recommendation for the negative response.

Another important point is the PLM adoption by Suppliers (SMEs). Introducing PLM system can help them to tackle the challenges of their processes. The importance of the organizational aspect is reinforced by the fact that PLM is based on the cooperation of various businesses; collaboration that takes place at different levels (Informal collaboration, project/process collaboration and extended collaboration, etc.).

\section{Conclusions and Further Work}

In this study we analysed the maturity levels of SMEs collaboration with OEM. Based on our proposed PLM axes (Strategy, Organization, Process and Tools), we classified the activities of each maturity level. This kind of classification is important for the identification of domain and person concerns by the activity.

As future work, we will develop the questionnaire based on the levels of maturity. The future questionnaire will include the results of the PLM adoption base on the table. This part will give an assessment of the capacity of SMEs, especially the ability to adopt PLM or not. As an example, indirect costs, manager, type of communication, size of SMEs, etc. We will integrate elements for adopting ICT (especially PLM) technology. For example, we can see the negative aspect of "Informal communication mode" in the process axis. It's related to SMEs practices, because in the most cases SMEs have an informal communication mode (according to their small size) and this kind of communication impact the PLM adoption.

Acknowledgement. Acknowledgement is made to European Union for the support of this research through the European Program INTERREG IVA France-Channel-UK by funding project entitled "Building an Expertise Network for an Efficient Innovation \& Training System (BENEFITS).

\section{References}

1. Mahdikhah, S., Messaadia, M., Baudry, D., Gao, J., Evans, R.: A Business Process Modelling Approach to Improve OEM and Supplier Collaboration. Journal of Advanced Management Science 2(3), 246-253 (2014)

2. Panetto, H., Berio, G., Benali, K., Boudjlida, N., Petit, M.: A Unified Enterprise Modelling Language for Enhanced Interoperability of Enterprise Models. In: 11th IFAC Symposium on Information Control Problems in Manufacturing, INCOM 2004, Salvador, Brazil (2004) 
3. Xiao-li, Q., Hong, Y., Xi-ying, W., Ming-yuan, C.: Information shares of network manufacturing system based on STEP and XML. Journal of Computer Integrated Manufacturing System 8(7), 293-316 (2002) (Chinese)

4. Calvi, R., Le Dain, M., Harbi, S., Bonottoo, V.: How to manage Early Supplier Involvement (ESI) into the New Product Development Process (NPDP): several lessons from a French study. In: 10th International Annual IPSERA Conference, Jönköping, Sweden (2001)

5. Ming, X.G., Yan, J.Q., Wang, X.H., Li, S.N., Lu, W.F., Peng, Q.J., Ma, Y.S.: Collaborative process planning and manufacturing in product lifecycle management. Computers in Industry 59, 154-166 (2008)

6. Rangan, R.M., Rohde, S.M., Peak, R., Chadha, B., Bliznakov, P.: Streamlining product lifecycle processes: a survey of product lifecycle management. Journal of Computing and Information Science in Engineering Transaction of the ASME 5, 227-237 (2005)

7. PLM interest Group, http: / / www . plmig.com/

8. Messaadia, M., Belkadi, F., Eynard, B., Sahraoui, A.E.K.: System Engineering and PLM as an integrated approach for industry collaboration management. In: INCOM, Romania (2012)

9. Silventoinen, A., Papinniemi, J., Lampela, H.: A Roadmap for Product Lifecycle Management Implementation in SMEs. In: ISPIM Conference, Vienna, Austria, June 21-24 (2009) ISBN 978-952-214-767-7

10. Saksvuori, A., Immonen, A.: Product Lifecycle Management. Springer, Berlin (2008)

11. Siller, H., Estruch, A., Vila, C.: Modeling workflow activities for collaborative process planning with product lifecycle management tools. J. Intell. Manufacturing 19, 689-700 (2008)

12. Denkena, B., Shpitalni, P., Kowalski, G., Molcho, G., Zipori, Y.: Knowledge Management in Process Planning. Annals of the CIRP 56(1) (2007)

13. Pol, G., Merlo, C., Legardeur, J., Jared, G.: Implementation of collaborative design processes in to PLM systems. Int. J. Product Lifecycle Management 3(4) (2008)

14. Sudarsan, R., Fenves, S.J., Sriram, R.D., Wang, F.: A product information modeling framework for product lifecycle management. Computer-Aided Design 37(13), 1399-1411 (2005)

15. Germani, M., Mengoni, M., Peruzzini, M.: A QFD-based method to support SMEs in Benchmarking co-design tools. Computers in Industry 63, 12-29 (2012)

16. Peruzzini, M., Mengoni, M., Germani, M.: PLM benefits for networked SMEs. In: PLM11 8th International Conference on Product Lifecycle Management (2012)

17. Tang, D., Qian, X.: Product lifecycle management for automotive development focusing on supplier integration. Computers in Industry 59, 288-295 (2008) 